\title{
Male brain type women and female brain type men : Gender atypical cognitive profiles and their correlates
}

\section{Svedholm-Häkkinen, Annika M.}

2018-02-01

Svedholm-Häkkinen , A M , Ojala , S \& Lindeman , M 2018 , ' Male brain type women and female brain type men : Gender atypical cognitive profiles and their correlates ', Personality and Individual Differences, vol. 122 , pp. 7-12 . https://doi.org/10.1016/j.paid.2017.09.041

http://hdl.handle.net/10138/311317

https://doi.org/10.1016/j.paid.2017.09.041

cc_by_nc_nd

acceptedVersion

Downloaded from Helda, University of Helsinki institutional repository.

This is an electronic reprint of the original article.

This reprint may differ from the original in pagination and typographic detail.

Please cite the original version. 


\begin{abstract}
Gender differences exist in abilities, interests, and occupations. According to the Empathizing-Systemizing theory, the reason for all gender differences lies in the relative weights of two cognitive processes: women empathize more, which is useful in understanding people, while men systemize more, which means interpreting phenomena as rule-based systems. The terms "male and female brain type" refer to a heightened preference for one process over the other. We aimed to find out whether the gender atypical groups of male brain type women and female brain type men are more similar to the opposite sex than to their own in terms of a range of social, cognitive and personality variables. Female and male brain type groups were identified and compared within both genders in an online study $(\mathrm{N}=2983)$. The results show there are female brain type men and male brain type women, who are characterized by qualities more often associated with the opposite sex, and who have not been reached by prior research. Thus, these findings demonstrate that cognitive type is a more powerful predictor of certain characteristics than is biological sex.
\end{abstract}

Keywords: brain type, empathizing, systemizing, cognitive style, gender differences 


\section{Male brain type women and female brain type men: Gender atypical cognitive profiles and their correlates}

It is often proposed that men and women think differently or have different ways of perceiving and making sense of things. For example, femininity is commonly associated with emotions and masculinity with logic. Femininity and masculinity are perceived to entail different skills, interests, and vocations (see e.g., Baron-Cohen, 2002, 2003; Nettle, 2007). The influence of socially prescribed, gender-based norms and expectations is a widely researched topic, but the kinds of cognition that could play a role in producing observable gender differences are not well understood.

Gaining more information concerning gender-dependent cognition can develop our view of how gender-related social phenomena are created. For example-a gender-based division still exists among occupational fields. In the USA, women's representation is still the highest in people-focused fields (e.g. helping professions such as clinical psychology, and clerical work) and the lowest in science, technology, engineering, and mathematics (STEM) fields (National Science Foundation, 2015).

Different explanations have been offered for this traditional division between men's and women's occupations. For example, lack of early experience with topics such as engineering and physics, and gender gaps in self-efficacy have been offered as explanations of why women are underrepresented in STEM fields (Cheryan, Ziegler, Montoya, \& Jiang, 2017). However, there are likely to still be unidentified structures underlying the gender segregation in working life. New approaches that go beyond the superficial level of biological sex and address cognitive structures have been called for (Lai et al., 2012). This is crucial for both scientific and practical reasons: knowledge guides the efforts and social policies designed to increase equality. The study at hand aims at increasing our understanding of gendered phenomena by investigating empathizing and systemizing (Baron-Cohen, 2002, 
2003). Previous work has investigated whether these are among the cognitive mechanisms mediating sex differences in career choices (Wright, Eaton, \& Skagerberg, 2015) but the present study is the first to focus on the psychological profiles of people who differ from the cognitive profile typically associated with their gender.

\subsection{Systemizing and empathizing as the essential difference}

Baron-Cohen (2003) has proposed the "empathizing-systemizing" theory as an explanation for psychological sex differences. According to this theory, empathizing and systemizing are not merely psychological dimensions that correlate with other attributes, but rather they are the fundamentally significant cognitive dimensions that create gender differences and comprise the essential difference between men and women.

Empathizing is defined as the "drive to identify another person's emotions and thoughts, and to respond to these with an appropriate emotion" (Baron-Cohen, 2002, p. 248). This allows a person to predict human behavior and care about others' feelings. On average, women empathize more than do men (Baron-Cohen, 2002).

The concept of systemizing is derived from the concept of folk physics. Systemizing has been defined as "the drive to analyse the variables in a system, to derive the underlying rules that govern the behavior of a system" (Baron-Cohen, 2002, p. 248), where a system is anything that takes inputs and delivers outputs, for example mathematics or libraries (BaronCohen, 2002; Wakabayashi et al., 2007). On average, men spontaneously use systemizing more than do women (Baron-Cohen, 2002).

Both systemizing and empathizing allow us to make sense of events and form reliable predictions, but they are useful in different contexts (Baron-Cohen, 2002). Systemizing allows one to understand the physical world. Empathizing, in turn, is the most powerful way of understanding and predicting the social world and human behavior. Because of this, 
differences in systemizing and empathizing may lead to different abilities, which vary in usefulness among different occupational fields.

\subsection{The male and female brain types}

The concept of brain type (Baron-Cohen, 2002) refers to the relative weight of the two key dimensions in an individual's characteristic way of making sense of things: We all have both systemizing and empathizing skills and interests, but for some individuals, one dimension is more developed than the other. The relative development of empathizing and systemizing leads to categories, such as the female brain type, where empathizing is more developed than systemizing, and the male brain type, where systemizing is more developed than empathizing.

Importantly, Baron-Cohen (2002) does not suggest a categorical difference between men and women. On the contrary, his central claim involves average differences: because more men than women have the systemizing brain type, and more women than men have the empathizing brain type, this creates gender differences in population averages. In the present study, we are going to focus for the first time on the individuals who are not representative of the average, but who show a cognitive profile atypical of their gender: women with a systemizing, "male" brain type, and men with an empathizing, "female" brain type. This will provide a crucial test of whether cognitive types indeed explain — better than biological sexwhy individuals have the characteristics that they do.

\subsection{Known gender differences}

Men on average have been found to have a preference for working with things, while women prefer working with people (Su, Rounds, \& Armstrong, 2009), and a systemizing profile is associated with studying physical sciences, while an empathizing profile is more common among humanities students (Billington, Baron-Cohen, \& Wheelwright, 2007). Thus we hypothesize that even among women, the male brain type is associated with working in 
systemizing-focused fields, and that even among men, the female brain type is associated with working in empathizing-focused fields. In addition, we hypothesize that compared to female brain type women, male brain type women have received higher grades in mathematics and physics, and that compared to male brain type men, female brain type men have received lower grades in mathematics and physics.

Women, on average, have stronger aesthetic, artistic and social interests while men have more practical and investigative interests, and stronger interests in technology (Su et al., 2009; Twenge, 1999). Here we hypothesize that individuals exhibiting the gender atypical brain types will have hobbies that are more in line with those of the opposite sex than with those of the individuals exhibiting the typical brain types.

On average, women focus more on the quality of social relationships and report higher connectedness and empathy within relationships than do men (Baron-Cohen \& Wheelwright, 2004). As empathizing has been associated with more social support and with the maintenance of larger numbers of social relationships (Nettle, 2007), we hypothesize that in both genders, the female brain type will be associated with increased social connectedness when compared to the male brain type.

Finally, one possible factor contributing to observed sex differences is sex role identity. Sex role identity has been classically defined as an acquired self-concept of an individual's degree of masculinity or femininity (Kagan, 1964), and it has been found to influence the development of same-sex-typed attributes (Reilly \& Neumann, 2013). Therefore, we hypothesize that the male brain type groups score higher in masculinity and lower in femininity than female brain type groups, and vice versa, within both genders.

In sum, the topic of this study is whether women exhibiting a cognitive profile typical of men have qualities typically associated with men; and similarly, whether men exhibiting a cognitive profile typical of women have qualities that are more often associated with women. 


\section{Method}

\subsection{Participants and procedure}

The participants were 2983 Finnish volunteers (65\% female, mean age 28 years, $S D=$ 8.87, range 15-69) who were recruited from internet discussion forums, student mailing lists, and a research volunteer pool. Of the participants, $27 \%$ were working, $64 \%$ were students, and $9 \%$ were otherwise occupied. Seven percent had completed primary school education, $56 \%$ upper secondary school and/or vocational school education, $37 \%$ had a polytechnic and/or university degree, and $1 \%$ a doctorate degree.

The recruitment messages included a hyperlink to the online questionnaire. Participants were informed that the study concerned thinking and personality. They were given 3 weeks to fill in the survey, either in one sitting or by saving their responses and continuing later. As compensation for their effort, all participants received a thinking style profile based on their responses to the Actively Open-Minded Thinking Scale (Stanovich \& West, 1997).

Of the 3086 people who originally participated in the study, 105 were excluded: Two because their comments revealed that they had not completed the survey seriously, and 103 because of missing information.

\subsection{Measures}

2.2.1 Empathizing and systemizing. We used the 15-item version of the Empathy Quotient (EQ) scale (Muncer \& Ling, 2006). The EQ-Short $(\alpha=.81)$ measures cognitive empathy, social skills, and emotional reactivity. Systemizing was assessed using the 18 -item version of the Systemizing Quotient (SQ) scale (Ling, Burton, Salt, \& Muncer, 2009). The SQ-Short $(\alpha=.85$ ) focuses on technicity, topography, DIY and structure. On both the EQ and the SQ, the original scoring method was used, whereby the 4-point response scale $(1=$ 
strongly disagree, $4=$ strongly agree) was converted into scores of $0,0,1$, and 2 . The sums of these scores were then calculated. In cases with less than $25 \%$ of the answers missing, missing values were substituted with the participant's average score. The distributions of these variables among each sex are presented in Figures 1 and 2.

To operationalize the male brain type and the female brain type, SQ and EQ scores ( $\mathrm{r}$ $=-.14, p<.001)$ were converted onto the same scale. Following Wakabayashi et al. (2006), brain type scores were then calculated by subtracting EQ scores from SQ scores. The distributions of the brain type variable are presented in Figure 3.

Following Baron-Cohen (2002), this brain type measure was used to identify four groups of participants for closer analysis: 994 female brain type women, 132 female brain type men (brain type $\leq 1 \mathrm{SD}$ below the mean), and 152 male brain type men (brain type $\geq 1$ SD above the mean). In the case of male brain type women, the group of women scoring $\geq 1$ SD above mean proved too small (47 people), wherefore the 90th percentile point, located 0.80 SD above the mean, was substituted as the cut-off point, resulting in 201 male brain type women to analyze.

Insert Figures 1, 2, and 3 here

2.2.2 Correlates. Occupational or educational field was investigated using two different measures from Svedholm-Häkkinen and Lindeman (2016). First, to distinguish between systemizing-oriented and empathizing-oriented fields, participants selected their field from a list of 22 options, and those who chose the health care industry, education, psychology, and other work in social services or human resources were classified as working in an empathizing-oriented field, while physics, chemistry or astronomy, mathematics, IT and technology were classified as systemizing-focused occupations. Second, the participants rated 
the importance of the following focus areas in their work or study: 1) data and facts, 2) ideas, 3) people (encountering people in e.g. helping, educating, informing, services, entertainment, sales, or motivating), or 4) things (e.g. machinery, materials, or tools as the focus of the work, not only as instruments). The importance of each of the four focus areas was rated on a 4point scale $(1=$ no focus, $4=$ high focus $)$, and participants were asked to give the highest rating to only one of the focus areas. Only the foci on people and things were included in the analyses.

School grades (latest grades from basic education and general upper secondary education) in mathematics and physics were requested as part of participants' background information (scale: 4 = fail, $10=$ excellent $)$.

As in Svedholm-Häkkinen and Lindeman (2016), participants rated whether they were interested in 24 hobbies statistically more preferred by one gender or the other. Examples of hobbies that men tend to report more often than women were watching sports programs and playing computer games, and examples of women's typical hobbies were clothes or fashion and group fitness classes. Feminine and a masculine hobby scores were formed as the number of hobbies checked in each category divided by the number of all hobbies checked.

Social connectedness was measured using the Friendship Scale (Hawthorne, 2006), which consists of six items $(\alpha=.82)$ relating to dimensions of isolation or connectedness, rated on a 4-point scale $(1=$ almost always, $4=$ not at all $)$. An example item is "I find it easy to get along with people".

Sex role identity was measured with the 20-item Bem Sex Role Inventory (SRI; Bem, 1981). The subscales used include traditionally masculine $(\alpha=.84)$ and feminine $(\alpha=.89)$ characteristics. Participants rated how well each of the characteristics described them using a 7-point scale $(1=$ hardly ever, 7 = always or almost always $)$. The masculine scale includes 
characteristics such as "independent" and "confident." Examples of the feminine subscale include "understanding" and "considerate of others' feelings."

\section{Results}

Table 1 demonstrates the association between brain type and occupational or educational field. As the table shows, the clear majority in each brain type were occupied in the hypothesized fields. Male brain type women worked or studied in systemizing-related fields and female brain type women in empathizing-related fields more often than would be expected under the null hypothesis of no association, $\chi^{2}(1)=137.416, p<.001, \phi=.59, p$ $<.001$. Female brain type men worked or studied in empathizing-related fields and male brain type men in systemizing-related fields more often than would be expected if there was no association, $\chi^{2}(1)=34.181, p<.001, \phi=.55, p<.001$.

Insert Tables 1 and 2 here

Table 2 shows that male brain type women rated their occupational focus on people as being lower and their focus on things as being higher than did female brain type women. Likewise, female brain type men rated their occupational focus on people as being higher, and their focus on things as being lower, than did male brain type men.

As Table 3 shows, the hypothesized differences between the brain types were found in terms of school performance in physics and mathematics, in hobbies, and on social connectedness. Among both women and men, brain type was associated with feminine sex role identity, but not with masculine sex role identity.

Insert Table 3 here 


\section{Discussion}

The present study is not the first to note that people with gender atypical cognitive profiles exist. In fact, Baron-Cohen (2002, p. 249) has noted, "some women have the male brain type, and some men have the female brain type, or aspects of it." However, while previous work has focused on the large majority of men with a systemizing brain type and women with an empathizing profile, the present study was the first to expressly focus on the atypical minorities. Overall, the results of the current study indicate that the gender atypical brain types are linked to the interests and skills more often associated with the opposite sex.

In occupational or educational areas, female brain type men and women had an increased likelihood of working in fields or studying subjects that relate to people or empathizing and are traditionally considered to be feminine. Similarly, male brain type men and women were both likely to be occupied in areas that require systemizing, which are typically seen as masculine. While systemizing has been associated with success and interest in technology and the STEM fields (Nettle, 2007; Ruzich et al., 2015; Su et al., 2009), and empathizing with skills and interests related to people (Baron-Cohen, 2003; Su et al., 2009), the link between brain type and skills and interest in individuals exhibiting the gender atypical brain types had not been established or studied before. Taken together with previous results, which show that brain types explain occupations, interests and school grades even when controlling for biological sex (Svedholm-Häkkinen \& Lindeman 2016), the findings here indicate that just as Baron-Cohen (2003) suggests, a simple appeal to differences between men and women is not enough to constitute a natural explanation for the gendered structures in working life: the gender atypical brain type groups show that relying on such an explanation ignores parts of the population. Of course, the systemizing-empathizing theory does not account for the many important social factors influencing career choices, but the present results suggest that individuals to some extent choose occupations in line with their cognitive profiles irrespective of biological sex. 
Social connectedness was also associated with the female brain type in both women and men. While previous research has found women on average to have a higher level of empathizing when compared to men (Baron-Cohen, 2002, 2003; Baron-Cohen \& Wheelwright, 2004; Nettle, 2007), we found an association between a higher than average level of empathizing and people-related skills in men as well.

In terms of hobbies, too, individuals exhibiting the gender atypical brain types showed similarity to their opposite sex: male brain type women had more masculine hobbies and fewer feminine hobbies than did gender-typical women, and female brain type men had more feminine and fewer masculine hobbies compared to gender-typical men. Whereas previous research has found sex differences in hobbies (a-meta-analysis: Su et al., 2009), the results presented here suggest that the gender atypical brain types emerge as clear exceptions. It appears likely that the drives for empathizing and systemizing are connected to the kinds of activities individuals find interesting. For example, many masculine hobbies have a systematic quality that can make them interesting to high systemizers, be they men or women.

Feminine sex role identity was strongly associated with the female brain type in both men and women, further supporting E-S theory. However, masculine sex role identity was not associated with brain types, even though previous research indicates that masculine gender identity is linked to a high level of systemizing-type skills such as spatial ability (Reilly \& Neumann, 2013). One possible explanation for our results is that as many qualities associated with masculinity are typically assigned higher value than those associated with femininity (see e.g., Ely \& Myerson, 2000), there could be a higher threshold for men to describe themselves as more feminine than there is for women to do the reverse. Therefore, social acceptability may affect women and men differently not only in terms of how likely they are to pursue education and careers in the areas they are interested in, but also in terms of how 
likely they are to report their self-image in questionnaires. Future studies may therefore want to include measures of social desirability.

The general conclusion from the findings presented here is that the gender atypical brain types are associated with occupations, hobbies, and skills more commonly associated with the opposite sex. Prior research connects many stereotypically feminine qualities to average women and the female brain type, and many masculine qualities to average men and the male brain type (Baron-Cohen, 2003; Halpern, Straight, \& Stephenson, 2011). However, the research at hand adds to this knowledge the discovery that the male brain type is associated with qualities typically considered to be masculine in both women and men, and the female brain type, not only for women but also for men, is linked to qualities typically seen as feminine. Thus, future research should take into consideration that male brain type women and female brain type men also exist and are not represented in studies focusing on identifying gender-based effects.

\subsection{Limitations}

While the results show an overall connection between cognitive profiles and the investigated qualities, some limitations must be considered. The distributions of the brain types in the sample used did not in every regard follow the general distribution established by Baron-Cohen (2003): among men, brain type was quite evenly distributed instead of shifted toward the male brain type, while for women, the female brain type was far more common than the male brain type, to the point that the grouping principle had to be adjusted. Future studies should investigate whether the distributions of brain types, as well as the correlates of atypical cognitive profiles, replicate in more optimally distributed data sets and whether they vary by societal factors such as equality and social structures.

Moreover, some of the present effect sizes were small. 


\subsection{Conclusions and future prospects}

Decades of research has looked at sex differences in cognition and other psychological attributes, but no definitive explanation for their origin has been agreed upon. Baron-Cohen (2002) proposes that average sex differences on cognitive, social, and personality attributes are not directly due to biological sex, but indirectly to women's typically higher relative tendency to empathize, or to understand people, and men's typically higher relative tendency to systemize, or to understand deterministic phenomena (BaronCohen, Knickmeyer, \& Belmonte, 2005). However, in addition to typical individuals, there is much value in studying those individuals who are atypical of their sex. This has the potential to test whether empathizing and systemizing are such powerful predictors of gendered phenomena as the E-S theory suggests. By the present results, they are, as empathizing and systemizing predict people's occupations, interests, hobbies, and skills even at the fringes of the distributions: among women who are strong systemizers but weak empathizers, and among men who are strong empathizers but weak systemizers.

Thus, average cognitive sex differences in occupations, interests, and self-image are not at dispute, but a more complex picture including the gender atypical brain types is emerging. In research on the Empathizing-Systemizing theory, the male brain type has received the most focus. This is understandable, as the empathizing-systemizing theory stems from autism research and primarily seeks to explain autism spectrum disorder as resulting from the extreme male brain type (Baron-Cohen, 2002; Lawson, Baron-Cohen, \& Wheelwright, 2004). However, it is also a theory on sex differences (Baron-Cohen, 2003), and in light of the results of this study, one that calls for additional research and focus not only on the typical brain types but also on the gender atypical brain types.

The value of studying cognitively gender atypical people lies in that it is a scientifically rigorous way to test the falsifiability of the theory. As the E-S theory can easily 
be criticized for circular reasoning and veiling old stereotypes about sex differences in new terminology, testing atypical individuals puts the theory to a stronger test. If empathizing and systemizing can explain the characteristics even of individuals who do not conform to gender stereotypes, as was the case here, this provides strong convergent evidence for the theory.

Perhaps the most societally important conclusion from this study is that male brain type women and female brain type men represent a previously unknown factor in terms of a variety of gendered phenomena. The existence of these gender atypical brain types suggests that research on sex differences may not be able to fully reach the underlying causes of such differences by inferring causal connections based on observed average sex differences. Due to the average differences between men and women in the drives to empathize and systemize, a superficial look into gendered phenomena may give the appearance of simple sex differences in a variety of areas, including occupations, hobbies, social skills, and gender identity. The results presented here suggest that considering both brain types in both sexes can help build a more complete understanding in gender-related areas of inquiry.

\section{References}

Baron-Cohen, S. (2002). The extreme male brain theory of autism. Trends in Cognitive Sciences, 6, 248-254. doi: 10.1016/S1364-6613(02)01904-6

Baron-Cohen, S. (2003). The Essential Difference: Male and Female Brains and the Truth about Autism. New York, NY: Basic Books.

Baron-Cohen, S., Knickmeyer, R. C., \& Belmonte, M. K. (2005). Sex differences in the brain: Implications for explaining autism. Science, 310, 819-823. doi:

\subsection{6/science. 1115455}

Baron-Cohen, S., Richler, J., Bisarya, D., Gurunathan, N., \& Wheelwright, S. (2003). The systemizing quotient: an investigation of adults with Asperger syndrome or fighfunctioning autism, and normal sex differences. Philosophical Transactions of the 
Royal Society of London. Series B, Biological Sciences, 358, 361-374. doi: 10.1098/rstb.2002.1206

Baron-Cohen, S., \& Wheelwright, S. (2004). The empathy quotient: an investigation of adults with Asperger syndrome or high functioning autism, and normal sex differences. Journal of Autism and Developmental Disorders, 34, 163-175. doi: 10.1023/B:JADD.0000022607.19833.00

Bem, S. (1981). Bem Sex-Role Inventory. Palo Alto, CA: Mind Garden.

Billington, J., Baron-Cohen, S., \& Wheelwright, S. (2007). Cognitive style predicts entry into physical sciences and humanities: Questionnaire and performance tests of empathy and systemizing. Learning and Individual Differences, 17, 260-268. doi: 10.1016/j.lindif.2007.02.004

Cheryan, S., Ziegler, S. A., Montoya, A. K., \& Jiang, L. (2017). Why are some STEM fields more gender balanced than others? Psychological Bulletin, 143, 1-35. doi: $10.1037 /$ bul0000052

Connellan, J., Baron-Cohen, S., Wheelwright, S., Batki, A., \& Ahluwalia, J. (2000). Sex differences in human neonatal social perception. Infant Behavior and Development, 23, 113-118. doi: 10.1016/S0163-6383(00)00032-1

Davis, M. H. (1983). Measuring individual differences in empathy: evidence for a multidimensional approach. Journal of Personality and Social Psychology, 44, 113126. doi: $10.1037 / 0022-3514.44 .1 .113$

Decety, J., \& Jackson, P. L. (2014). The functional architecture of human empathy. Behavioral and Cognitive Neuroscience Reviews, 3, 71-100. doi: $10.1177 / 1534582304267187$ 
Ely, R. J., \& Myerson, D. E. (2000). Theories of gender in organizations: A new approach to organizational analysis and change. Research in Organizational Behavior, 22, 103151. doi: 10.1016/S0191-3085(00)22004-2

Halpern, D. F., Straight, C., \& Stephenson, C. (2011). Beliefs about cognitive gender differences: Accurate for direction, underestimated for size. Sex Roles, 64, 336-347. doi: $10.1007 / \mathrm{s} 11199-010-9891-2$

Hawthorne, G. (2006). Measuring social isolation in older adults: Development and initial validation of the Friendship Scale. Social Indicators Research, 77, 521-548. doi: $10.1007 / \mathrm{s} 11205-005-7746-\mathrm{y}$

Kagan, J. (1964). Acquisition and significance of sex-typing and sex-role identity. In M. L. Hoffman \& L. W. Hoffman (Eds.), Review of child development research (Vol. 1, pp. 137-167). New York: Russell Sage.

Lai, M.-C., Lombardo, M. V., Chakrabarti, B., Ecker, C., Sadek, S. A., Wheelwright, S. J., . . . Baron-Cohen, S. (2012). Individual differences in brain structure underpin empathizing-systemizing cognitive styles in male adults. NeuroImage, 61, 1347-1354. doi: 10.1016/j.neuroimage.2012.03.018

Lawson, J., Baron-Cohen, S., \& Wheelwright, S. (2004). Empathising and systemising in adults with and without Asperger Syndrome. Journal of Autism and Developmental Disorders, 34, 301-310. doi: 10.1023/B:JADD.0000029552.42724.1b

Ling, J., Burton, T. C., Salt, J. L., \& Muncer, S. J. (2009). Psychometric analysis of the systemizing quotient (SQ) scale. British Journal of Psychology, 100, 539-552. doi: $10.1348 / 000712608 X 368261$

Muncer, S. J., \& Ling, J. (2006). Psychometric analysis of the empathy quotient (EQ) scale. Personality and Individual differences, 40, 1111-1119. doi: 10.1016/j.paid.2005.09.020 
National Science Foundation, National Center for Science and Engineering Statistics (2017). Women, Minorities, and Persons with Disabilities in Science and Engineering: 2017. Special Report NSF 17-310. Arlington, VA. Retrieved from http://www.nsf.gov/statistics/wmpd/.

Nettle, D. (2007). Empathizing and systemizing: What are they, and what do they contribute to our understanding of psychological sex differences? British Journal of Psychology, 98, 237-255. doi: 10.1348/000712606X117612

Reilly, D., \& Neumann, D. L. (2013). Gender-role differences in spatial ability: a metaanalytic review. Sex Roles, 68, 521-535. doi: 10.1007/s11199-013-0269-0

Ruzich, E., Allison, C., Chakrabarti, B., Smith, P., Musto, H., Ring, H., \& Baron-Cohen, S. (2015). Sex and STEM occupation predict autism-spectrum quotient (AQ) scores in half a million people. PloS One, 10, 1-15. doi: 10.1371/journal.pone.0141229

Stanovich, K. E., \& West, R. F. (1997). Reasoning independently of prior belief and individual differences in actively open-minded thinking. Journal of Educational Psychology, 89, 342-357. doi: 10.1037/0022-0663.89.2.342

Su, R., Rounds, J., \& Armstrong, P. I. (2009). Men and things, women and people: A metaanalysis of sex differences in interests. Psychological Bulletin, 135, 859-884. doi: $10.1037 / \mathrm{a} 0017364$

Svedholm-Häkkinen, A. M., \& Lindeman, M. (2016). Testing the Empathizing-Systemizing theory in the general population: Occupations, vocational interests, grades, hobbies, friendship quality, social intelligence, and sex role identity. Personality and Individual Differences, 90, 365-370. doi: 10.1016/j.paid.2015.11.044

Wakabayashi, A., Baron-Cohen, S., Uchiyama, T., Yoshida, Y., Kuroda, M., \& Wheelwright, S. (2007). Empathizing and systemizing in adults with and without autism spectrum 
conditions: cross-cultural stability. Journal of Autism and Developmental Disorders, 37, 1823-1832. doi: 10.1007/s10803-006-0316-6

Wakabayashi, A., Baron-Cohen, S., Wheelwright, S., Goldenfeld, N., Delaney, J., Fine, D., . . . Weil, L. (2006). Development of short forms of the Empathy Quotient (EQ-Short) and the Systemizing Quotient (SQ-Short). Personality and Individual Differences, 41, 929-940. doi: 10.1016/j.paid.2006.03.017

Wright, D. B., Eaton, A. A., \& Skagerberg, E. (2015). Occupational segregation and psychological gender differences: How empathizing and systemizing help explain the distribution of men and women into (some) occupations. Journal of Research in Personality, 54, 30-39. doi: 10.1016/j.jrp.2014.06.004 
Table 1

Occupational or educational field in gender atypical and typical brain types

Brain type

Occupational/

\begin{tabular}{lllll} 
Sex & educational field & Male & Female & $n$ \\
\hline Women & Empathizing & $11(22.9 \%)$ & $316(91.1 \%)$ & 327 \\
& Systemizing & $37(77.1 \%)$ & $31(8.9 \%)$ & 68 \\
& Total & $48(100 \%)$ & $347(100 \%)$ & 395 \\
\hline Men & Empathizing & $6(7.9 \%)$ & $22(57.9 \%)$ & 28 \\
& Systemizing & $70(92.1 \%)$ & $16(42.1 \%)$ & 86 \\
& Total & $76(100 \%)$ & $38(100 \%)$ & 114 \\
\hline
\end{tabular}


Table 2

Occupational focus in gender atypical and typical brain types

\begin{tabular}{|c|c|c|c|c|c|c|}
\hline \multirow[b]{4}{*}{ Sex } & \multirow{4}{*}{$\begin{array}{l}\text { Occupational } \\
\text { focus }\end{array}$} & \multicolumn{2}{|l|}{ Brain type } & \multirow{2}{*}{\multicolumn{2}{|c|}{ Test of group difference }} & \multirow{3}{*}{ Effect size } \\
\hline & & \multirow{3}{*}{$\begin{array}{l}\text { Male } \\
M(S D)\end{array}$} & \multirow{3}{*}{$\begin{array}{l}\text { Female } \\
M(S D)\end{array}$} & & & \\
\hline & & & & & & \\
\hline & & & & $t(d f)$ & $p$ & (Cohen's D) \\
\hline \multirow[t]{2}{*}{ Women } & People & $2.55(0.98)$ & $3.21(0.93)$ & $8.977(1177)$ & $<.001$ & .69 \\
\hline & Things & $2.01(1.01)$ & $1.68(0.83)$ & $-5.571(1177)$ & $<.001$ & .35 \\
\hline \multirow[t]{2}{*}{ Men } & People & $2.49(0.87)$ & $3.21(0.90)$ & $-6.773(278)$ & $<.001$ & .81 \\
\hline & Things & $2.68(1.11)$ & $2.13(1.03)$ & $4.334(281)$ & $<.001$ & .51 \\
\hline
\end{tabular}


Table 3

School grades, Hobbies, Cognitive Empathic Ability, Social Connectedness, and Sex Role Identity in gender atypical and typical brain types

\begin{tabular}{|c|c|c|c|c|c|c|}
\hline \multirow[b]{3}{*}{ Sex } & \multirow[b]{3}{*}{ Variable } & \multicolumn{2}{|c|}{ Brain type } & \multicolumn{2}{|c|}{ Test of group difference } & \multirow[b]{2}{*}{ Effect size } \\
\hline & & & & & & \\
\hline & & male & female & $t(d f)$ & $p$ & (Cohen's D) \\
\hline \multirow[t]{7}{*}{ Women } & Physics grade & 8.27 & 7.78 & $-4.900(1183)$ & $<.001$ & .39 \\
\hline & Mathematics grade & 8.44 & 7.90 & $-5.163(1185)$ & $<.001$ & .41 \\
\hline & Feminine hobbies & .26 & .42 & $10.545(1161)$ & $<.001$ & .86 \\
\hline & Masculine hobbies & .20 & .09 & $11.080(1161)$ & $<.001$ & .78 \\
\hline & Friendship & 2.51 & 3.21 & $16.714(1158)$ & $<.001$ & 1.19 \\
\hline & Feminine SRI & 4.05 & 5.42 & 22.673(1192) & $<.001$ & 1.56 \\
\hline & Masculine SRI & 4.53 & 4.51 & $-0.261(1193)$ & .794 & .02 \\
\hline \multirow[t]{7}{*}{ Men } & Physics grade & 8.29 & 7.40 & $5.959(280)$ & $<.001$ & .70 \\
\hline & Mathematics grade & 8.36 & 7.41 & $6.137(280)$ & $<.001$ & .73 \\
\hline & Feminine hobbies & .13 & .20 & $-2.881(278)$ & $<.001$ & .48 \\
\hline & Masculine hobbies & .40 & .31 & $3.841(278)$ & $<.001$ & .45 \\
\hline & Friendship & 2.46 & 3.12 & $11.001(278)$ & $<.001$ & 1.33 \\
\hline & Feminine SRI & 3.77 & 5.41 & $15.671(282)$ & $<.001$ & 1.88 \\
\hline & Masculine SRI & 4.63 & 4.61 & $.150(282)$ & .881 & .02 \\
\hline
\end{tabular}




\section{Figure captions}

Fig. 1 Distribution of the Empathy Quotient for women and me

Fig. 2 Distribution of the Systemizing Quotient for women and men

Fig. 3 Distribution of brain type for women and men. Low values indicate an empathizing, "female" brain type and high values indicate a systemizing, "male" brain type 

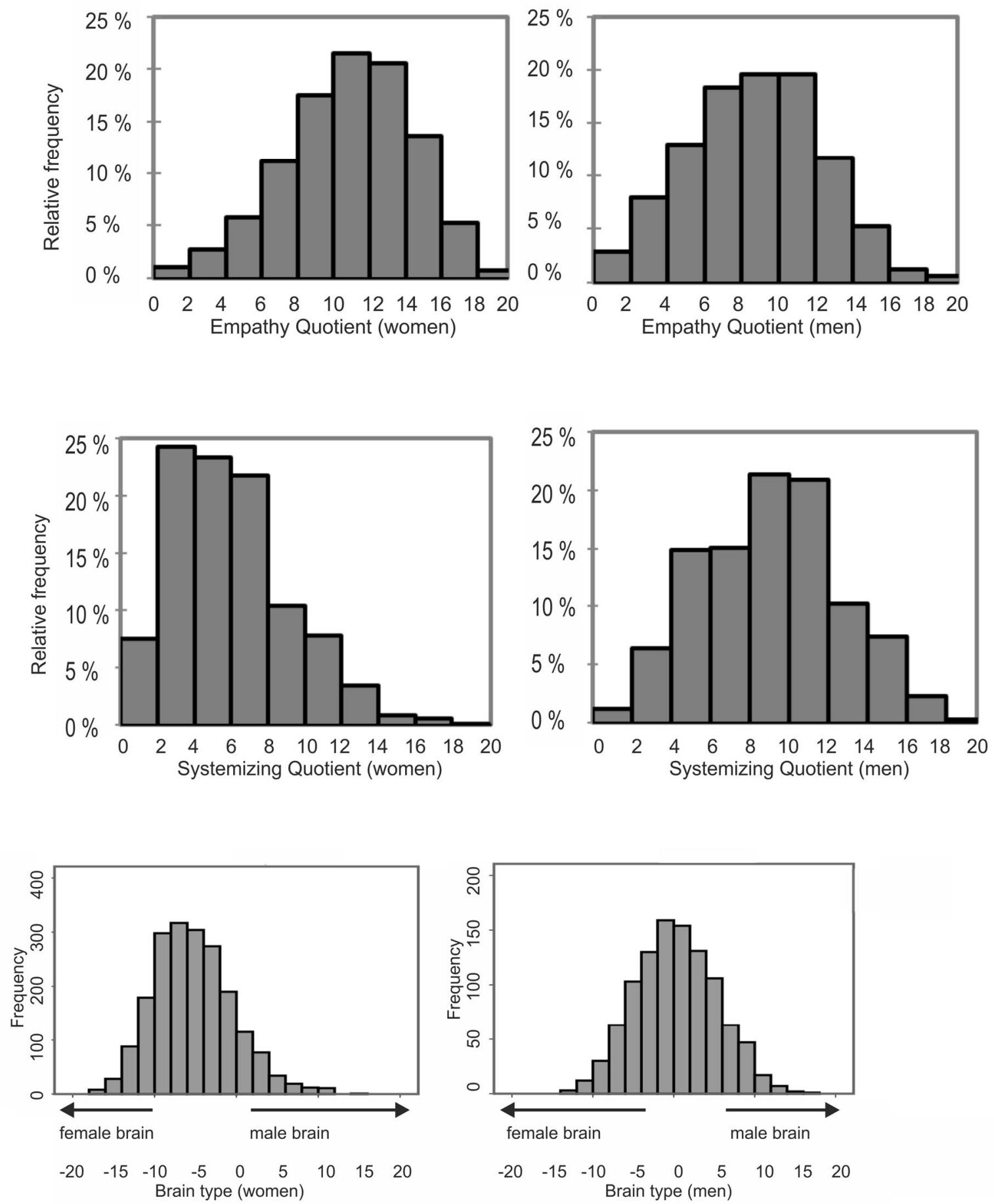